\title{
Preconception Optimization of Glucose and Insulin Metabolism in Women Wanting to Conceive - High Rate of Spontaneous Conception Prior to Planned Assisted Reproduction
}

\section{Präkonzeptionelle Optimierung des Glukose- und Insulin- stoffwechsels bei Kinderwunschpatientinnen - hohe Spontan- konzeptionsrate vor geplanter assistierter Reproduktion}

Authors

Sara Fill Malfertheiner ${ }^{1,2}$, Dagmar Gutknecht ${ }^{1}$, Monika Bals-Pratsch ${ }^{1}$

Affiliations

1 Profertilita - Fachklinik für Fruchtbarkeitsmedizin, Regensburg, Germany

2 Klinik für Geburtshilfe und Frauenheilkunde der Universität Regensburg - Krankenhaus Barmherzige Brüder Klinik St. Hedwig, Regensburg, Germany

Key words

gestational diabetes, early-onset gestational diabetes, ART, metformin

Schlüsselwörter

Gestationsdiabetes, früh einsetzender Gestationsdiabetes, FREGDM, ART, Metformin

$\begin{array}{ll}\text { received } & 23.6 .2017 \\ \text { revised } & 2.11 .2017 \\ \text { accepted } & 3.11 .2017\end{array}$

Bibliography

DOI https://doi.org/10.1055/s-0043-122279

Geburtsh Frauenheilk 2017; 77: 1312-1319 @ Georg Thieme

Verlag KG Stuttgart · New York | ISSN 0016-5751

Correspondence

Dr. Sara Fill Malfertheiner, MD, MHBA

University Medical Center Regensburg, Clinic St. Hedwig, Hospital of the Barmherzige Brueder, Department of Obstetrics and Gynecology

Steinmetzstraße 1-3, 93049 Regensburg, Germany

Sara.fillmalfertheiner@barmherzige-regensburg.de

$\Theta$

Deutsche Version unter:

https://doi.org/10.1055/s-0043-122279

\section{ABSTRACT}

Background A hyperglycemic metabolic status with insulin resistance can have a negative effect on fertility and pregnancy outcomes. The aim of this retrospective study was to investigate disorders of glucose and insulin metabolism in women wanting to conceive who conceived spontaneously prior to planned assisted reproduction (ART). Associated risk factors of patients in terms of live births and miscarriages were also analyzed.

Method Out of total study population of 589 pregnancies, the pregnancies of 129 women wishing to have children who conceived spontaneously prior to planned ART were analyzed in more detail. A $75 \mathrm{~g}$ OGTT (OGTT: oral glucose tolerance test) was carried out prior to conception and after determination of pregnancy, including glucose measurement and testing of insulin resistance. If anomalies or risk factors for gestational diabetes (GDM) were detected, patients received metformin therapy prior to conception (off-label use). The course and outcome of pregnancies in the defined cohort were recorded.

Results The rate of spontaneous conception before planned ART after treatment for disorders of glucose/insulin metabolism was $21.9 \%(n=129 / 589)$. $66.7 \%$ of the 129 pregnancies resulted in a live birth, 32 patients had a miscarriage. $76.0 \%$ of patients were treated with metformin (off-label use) for polycystic ovary syndrome (PCOS), positive risk profile for GDM, or abnormal glucose/insulin metabolism prior to conception. $55.8 \%$ of the cohort developed GDM. The insulin requirements of patients with GDM differed significantly depending on their metformin intake. $24.6 \%$ of GDM patients receiving metformin treatment developed GDM requiring insulin treatment compared to $53.8 \%$ who did not receive metformin medication. The PCOS rate in the study population who had live births was significantly higher $(57.0 \%)$ than in the group who had miscarriages (31.3\%). There were no significant differences with regard to rate of live births and rate of miscarriages with/without metformin treatment and GDM and metformin intake.

Conclusion The high rate of spontaneous conceptions in the cohort of women wishing to conceive emphasizes the importance of optimizing glucose/insulin metabolism prior to conception. The high rate of GDM in a cohort of pregnant women with a history of sterility also emphasizes the importance of expanding diagnostic testing for sterility to include the inves- 
tigation of glucose metabolism and testing for insulin resistance. It is possible that PCOS patients in particular could benefit from treatment with metformin prior to conception, and this could explain the high rate of live births in this patient cohort.

\section{ZUSAMMENFASSUNG}

Fragestellung Eine hyperglykämische Stoffwechsellage und eine Insulinresistenz können einen negativen Einfluss auf Fertilität und Schwangerschaftsoutcome haben. Ziel dieser retrospektiven Studie war die Untersuchung der Glukose- und Insulinstoffwechselstörungen von Kinderwunschpatientinnen mit Spontankonzeption vor geplanter assistierter Reproduktion (ART). Analysiert wurden assoziierte Risikofaktoren der Patientinnen in Bezug auf Lebendgeburt oder Abort.

Methodik Aus einer Gesamtkohorte von 589 Schwangerschaften wurden 129 Kinderwunschpatientinnen mit Spontankonzeption vor geplanter ART genauer analysiert. Präkonzeptionell sowie nach Feststellung einer Schwangerschaft erfolgte ein 75-g-oGTT (oGTT: oraler Glukosetoleranztest) mit Glukosemessung und Insulinresistenztestung. Bei Auffälligkeiten oder Risikofaktoren für Gestationsdiabetes (GDM) erfolgte eine präkonzeptionelle Metformintherapie (Off-LabelUse). Der Schwangerschaftsverlauf sowie das Schwangerschaftsoutcome der definierten Kohorte wurden erhoben.

Ergebnis Die Spontankonzeptionsrate vor geplanter ART nach therapeutischer Intervention bei Auffälligkeiten im Glu-
kose-/Insulinstoffwechsel lag bei $21,9 \% \quad(n=129 / 589)$. In $66,7 \%$ der 129 Schwangerschaften kam es zur Geburt, 32 Patientinnen erlitten einen Abort. 76,0\% wurden aufgrund eines polyzystischen Ovarsyndroms (PCOS), eines positiven GDMRisikoprofils oder präkonzeptionell auffälligen Glukose-/Insulinstoffwechsels mit Metformin (Off-Label-Use) behandelt. 55,8\% der Kohorte entwickelten einen GDM. Einen signifikanten Unterschied zeigten GDM-Patientinnen hinsichtlich des Insulinbedarfs in Abhängigkeit zur Metformineinnahme. 24,6\% der GDM-Patientinnen unter Metformintherapie entwickelten einen insulinbehandelten GDM, ohne Metforminmedikation 53,8\%. Die PCOS-Rate in der Studienpopulation mit Lebendgeburt war signifikant höher $(57,0 \%)$ als bei den Abortpatientinnen (31,3\%). Es zeigte sich kein signifikanter Unterschied hinsichtlich Geburt- und Abortrate mit/ohne Metformin sowie GDM und Metformineinnahme.

Schlussfolgerung Die hohe Spontankonzeptionsrate der Kinderwunschkohorte unterstreicht die Bedeutung der präkonzeptionellen Glukose-/Insulinstoffwechseloptimierung für die Fruchtbarkeit. Zudem unterstreicht die hohe Rate an GDM bei Schwangeren mit Sterilitätsanamnese die Wichtigkeit, die Sterilitätsdiagnostik auf die Untersuchung des Glukosestoffwechsels und Testung auf Insulinresistenz zu erweitern. Möglicherweise profitierten zudem gerade PCOS-Patientinnen von der präkonzeptionellen Metforminmedikation, was die hohe Lebendgeburtenrate in dieser Patientinnengruppe erklärt.

\section{Introduction}

Sterility affects between 8 and 12\% of all couples of reproductive age [1]. In addition to causes of acquired sterility such as tubal defects due to sexually transmitted disease, the main causes for the rise in female sterility rates recorded in recent years are overweight, obesity, polycystic ovary syndrome (PCOS) and increasing maternal age $[2,3]$.

It is known in assisted reproduction medicine that overweight can result in poorer oocyte quality, lower embryo development rates and lower chances of implantation [4]. The prevalence of obesity and type 2 diabetes mellitus (DM) has continually increased in recent years, particularly in women in the reproductive age group. Just under $25 \%$ of all women in Germany are obese and more than $50 \%$ are overweight [5]. Obesity, overweight, high maternal age and PCOS are risk factors for sterility but also for developing gestational diabetes [6]. Women with a history of sterility should be investigated for risk factors for gestational diabetes; if they have weight problems, PCOS, and higher maternal age, metabolic tests should be done prior to conception and treatment initiated where appropriate.

This retrospective study analyzed a patient cohort of 129 women wishing to have children who conceived spontaneously before having planned assisted reproduction (ART) out of a total patient cohort of 589 pregnancies. The aim of this retrospective evaluation was to analyze this defined cohort of patients $(n=129)$ who conceived spontaneously before ART and to define its risk profile with regard to age, body mass index, history of recurrent miscarriage, glucose and insulin metabolism, medication, complications of pregnancy, birth and GDM. The secondary aim of the study was to look for associated influences with regard to live births or miscarriages in the defined cohort. The risk profiles (in terms of glucose and insulin metabolism) of patients who conceived spontaneously and had live births were compared to those of women who had a miscarriage in early pregnancy.

\section{Patients and Method}

This retrospective study analyzed a cohort of 129 women wishing to become pregnant who attended a center for reproductive medicine between 1 July 2011 and 31 December 2013 for assisted reproductive treatment and who conceived before undergoing the planned ART treatment ( $\bullet$ Fig. 1). Out of a total of 589 pregnancies which occurred in the above-mentioned period, 460 pregnancies were the result of ART and 129 pregnancies were conceived spontaneously. Patients with positive $\beta$-hCG values $(\geq 5 \mathrm{IU} / \mathrm{I})$ in the above-mentioned period were included in the study.

Prior to conception, the patients underwent extensive diagnostic testing to determine causes of sterility and had a $75 \mathrm{~g}$ OGTT (OGTT: oral glucose tolerance test) with concurrent measurement of insulin and glucose (point in time - TP fasting/60/ $120 \mathrm{~min})$. Impaired glucose metabolism prior to conception was diagnosed if fasting glucose values were abnormal (100-125 mg/ 
dl, i.e. $5.6-6.9 \mathrm{mmol} / \mathrm{l})$ or glucose tolerance was impaired $(2 \mathrm{~h}$ plasma glucose within OGTT range of $140-199 \mathrm{mg} / \mathrm{dl}$, i.e. $7.8-$ $11.0 \mathrm{mmol} / \mathrm{l})$. In this study, disorders of glucose metabolism prior to conception were additionally defined as glucose values which exceeded threshold values for gestational diabetes (fasting glucose value $\geq 92 \mathrm{mg} / \mathrm{dl}, 1$-hour glucose value $\geq 180 \mathrm{mg} / \mathrm{dl}$ or 2 hour glucose value $\geq 153 \mathrm{mg} / \mathrm{dl}$ ) [7]. The following empirical threshold values for insulin metabolism were defined for the study: fasting $\geq 10 \mathrm{mU} / \mathrm{l}$, 1 -hour value $\geq 50 \mathrm{mU} / \mathrm{l}$, 2-hour value $\geq 25 \mathrm{mU} / \mathrm{l}$ ( $\bullet$ Table 1 ). Women who presented with abnormal glucose/insulin values prior to conception or had a history of risk factors for developing GDM were started on metformin treatment (off-label use). All women who became pregnant through spontaneous conception identified by positive $\beta$-hCG test results immediately had a 2nd diagnostic $75 \mathrm{~g}$ OGTT to test for early-onset gestational diabetes. If glucose values in early pregnancy were unremarkable, the OGTT was repeated between GW (week of gestation) $24+0$ and GW $27+6$, in accordance with the relevant guidelines [7]. The course of pregnancy and pregnancy outcome (live birth/miscarriage) were recorded for all women.

\section{Statistical Analysis}

The SPSS Statistics software package, version 22.0 (IBM Corp., New York, NY, USA) was used for data analysis. The level of significance was defined as $p<0.05$. Linear regression analysis and coefficient of determination $R^{2}$ were used to evaluate relationships between variables, with $R^{2}=0$ indicating no relationship and $R^{2}=1$ indicating that the entire variance of the dependent variable was explained by the independent variable.

\section{Results}

\section{Demographic data}

The rate of spontaneous conception in the described study population $(n=589)$ after diagnostic testing for sterility and prior treatment of abnormal glucose/insulin metabolic levels (nutrition counseling, physical exercise, metformin) was $21.9 \%(n=129)$. The most important demographic data of the women who conceived spontaneously are summarized in $\boldsymbol{\nabla}$ Table $\mathbf{2}$.

The BMI distribution of the study population according to the criteria of the WHO is shown in - Fig. 2; more than $70.0 \%$ of the women were of normal weight.

86 of the 129 patients (66.7\%) who conceived spontaneously gave birth to a healthy infant; $32(24.8 \%)$ women had a miscarriage. $33.3 \%(n=29)$ of the live births were delivered by C-section, the rate of premature deliveries was $10.0 \%$. The median birth weight was $3250 \mathrm{~g}$. In the overall evaluation, there was no statistically significant difference in birth weight between infants born to GDM mothers and those born to non-GDM mothers. Analysis of coagulation disorders, thyroid disease and previous ART showed no significant effect on rates of miscarriages and live births.

\section{Metformin}

98 women $(76.0 \%)$ were treated with metformin prior to conception because they had risk factors which predisposed them to de-
Pregnancies in the Center for Reproductive Medicine between July 1, 2011 and December 31, 2013 $\mathbf{n}=\mathbf{5 8 9}$

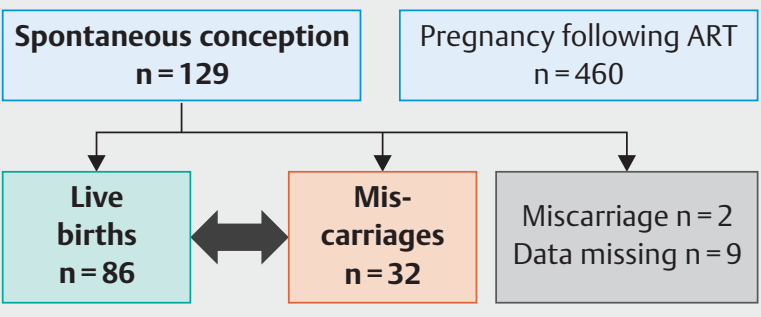

- Fig. 1 Flow chart of the study design.

- Table 1 Diagnostic threshold values in venous plasma for a diagnosis of gestational diabetes based on the IADPSG consensus recommendations (2010) and empirical insulin threshold values for a diagnosis of disorder of insulin metabolism.

\begin{tabular}{|l|l|l|l|}
\hline $\begin{array}{l}\text { Time of } \\
\text { measurement }\end{array}$ & $\begin{array}{l}\text { Glucose } \\
\text { value } \\
\text { (mg/d) }\end{array}$ & $\begin{array}{l}\text { Glucose } \\
\text { value } \\
\text { (mmol/I) }\end{array}$ & $\begin{array}{l}\text { Insulin } \\
\text { value } \\
(\mathbf{m U} / \mathbf{I})\end{array}$ \\
\hline Fasting & 92 & 5.1 & 10 \\
\hline After 1 hour & 180 & 10.0 & 50 \\
\hline After 2 hours & 153 & 8.5 & 25 \\
\hline
\end{tabular}

- Table 2 Demographic data and medical history of patients who conceived spontaneously after attending a center for reproductive medicine. Data are presented as means or percentages (absolute figures).

\begin{tabular}{|l|l|}
\hline & Study population $(\mathbf{n}=\mathbf{1 2 9})$ \\
\hline Age (years) & 32.74 \\
\hline Body mass index (BMI) & 23.51 \\
\hline Primary sterility & $46.5 \%(60)$ \\
\hline Secondary sterility & $53.5 \%(69)$ \\
\hline Nullipara & $74.4 \%(96)$ \\
\hline Multipara & $25.7 \%(33)$ \\
\hline Recurrent miscarriage & $43.3 \%(55)$ \\
\hline PCOS & $51.2 \%(66)$ \\
\hline Coagulation disorder & $22.5 \%(29)$ \\
\hline
\end{tabular}

velop GDM or PCOS or had abnormal glucose/insulin values. After starting with a low dose, the daily metformin intake of $74.5 \%$ $(n=73)$ of patients was $1500 \mathrm{mg} /$ day. $19.4 \%(n=20)$ of patients took $2000 \mathrm{mg}$ of metformin per day. 5.1\% $(n=5)$ of patients had individually adjusted doses of metformin because of fluctuating side effects. 


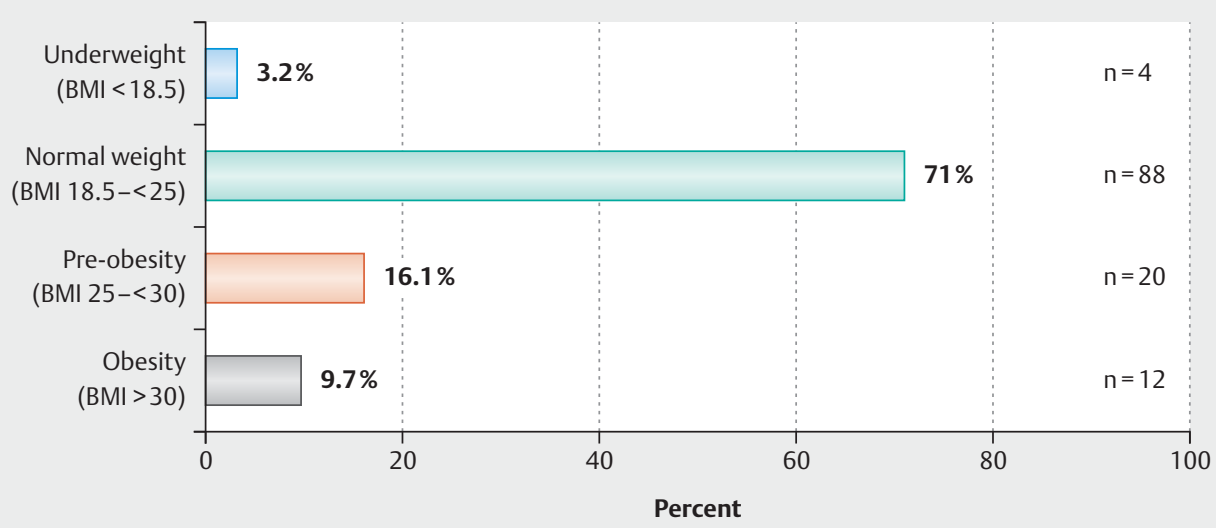

- Fig. 2 BMI distribution according to the criteria of the WHO.

Intake of metformin had no significant effect on miscarriage rates (75.0\% metformin intake) or rates of live births (76.7\% metformin intake) $(p=0.843)$.

\section{Disorders of glucose metabolism and gestational diabetes}

The analyzed 129 spontaneous pregnancies, broken down into gestational diabetes with a further subdivision into pathological OGTT, treatment, and pregnancy outcomes, are shown as a flow chart in $>$ Fig. 3 .

The baseline OGTT ( $n=95)$ prior to conception of $19.8 \%(n=8)$ of women showed glucose values which were higher than the diagnostic threshold values for gestational diabetes. Overall, $55.8 \%$ ( $n=72$ ) of the 129 patients developed GDM. In $84.6 \%$ of patients, GDM was already diagnosed in the 1 st trimester of pregnancy. Of the women who were diagnosed with a disorder of glucose metabolism even prior to conception, $77.8 \%(n=14)$ went on to develop GDM. Of the patients who had unremarkable values prior to conception, $62.3 \%(n=48)$ developed GDM during the course of pregnancy $(p=0.215)$. There was a significant difference $(p<0.05)$ in the group of GDM patients with regard to developing insulin dependence, and this difference depended on their metformin intake. $24.6 \%(n=14)$ of GDM patients receiving metformin developed insulin-requiring GDM, while the percentage of women with GDM requiring insulin who did not receive metformin treatment was $53.8 \%(n=7)$.

Overall, $31.1 \%(n=22)$ of women diagnosed with GDM had a positive familial risk profile. $63.3 \%(n=50)$ of women who had a live birth developed GDM during pregnancy. Of the women who had a miscarriage, only $46.9 \%(n=15)$ of women were diagnosed with GDM. Moreover, in our study population, a history of miscarriage and a maternal age of $>\mid<35$ years were not significant risk factors for developing GDM ( $p>0.05)$.

\section{Polycystic ovary syndrome}

The PCOS rate for the total study population was $51.6 \%(n=66)$. The PCOS rate for the cohort of women who had live births was significantly higher compared to that of the cohort of women who had miscarriages (57.0\%, $n=49$ vs. $31.3 \%, n=10 ; p<0.05)$. $27.3 \%$ of PCOS patients who were not treated with metformin $(n=13)$ had a miscarriage, while only $14.6 \%$ of women $(n=53)$ who received metformin had a miscarriage $(p=0.312) .54 .2 \%$ $(n=39)$ of patients with GDM had concomitant PCOS $(p=0.375)$. There was no statistical difference $(p=0.53)$ between the GDM rate in the group of PCOS patients who received metformin (60.4\%) and GDM rate of those who did not (53.8\%).

\section{Insulin resistance}

The empirically determined threshold insulin values (fasting value $\geq 10 \mathrm{mU} / \mathrm{l}, 1$-hour value $\geq 50 \mathrm{mU} / \mathrm{l}, 2$-hour value $\geq 25 \mathrm{mU} / \mathrm{l}$ ) were exceeded in $87.8 \%$ of patients whose insulin levels were measured prior to conception. The insulin sensitivity index (ISI) showed abnormal insulin values for $52.1 \%$ of patients and the HOMA index ( $\geq 2$ ) showed abnormal values for $26.0 \%$ of patients. In $56.0 \%$ of cases, women had PCOS in addition to insulin resistance. Of the patients who had insulin resistance even before they became pregnant, 63.7\% developed GDM. A preconception diagnosis of insulin resistance had no significant impact on whether the patient developed GDM $(p=0.844)$. As regards the birth rate, rate of miscarriages and development of GDM, there were no significant differences between women who had abnormal and those who had normal ISI or HOMA index values $(p=0.987)$. A significant correlation $(p=0.001)$ with a large effect size $\left(R^{2}=0.11\right)$ was found between the HOMA index and patients' BMI: the higher the BMI, the higher the HOMA index.

\section{Age and BMI}

When group comparisons were done to compare the group of women with miscarriages with the group of women who gave birth to a child, there was a significant difference $(p=0.019)$ with regard to patient age ( $\bullet$ Fig. 4 ). Of the group aged $<35$ years, $19.4 \%$ had a miscarriage; in contrast, the rate of miscarriages in the group aged $>35$ years was significantly higher at $39.1 \%$ $(p=0.032)$. In the group of patients with a history of miscarriage ( $\geq 2$ miscarriages), the rate of miscarriages was significantly higher $(p=0.009)(\triangleright$ Fig. 4). 


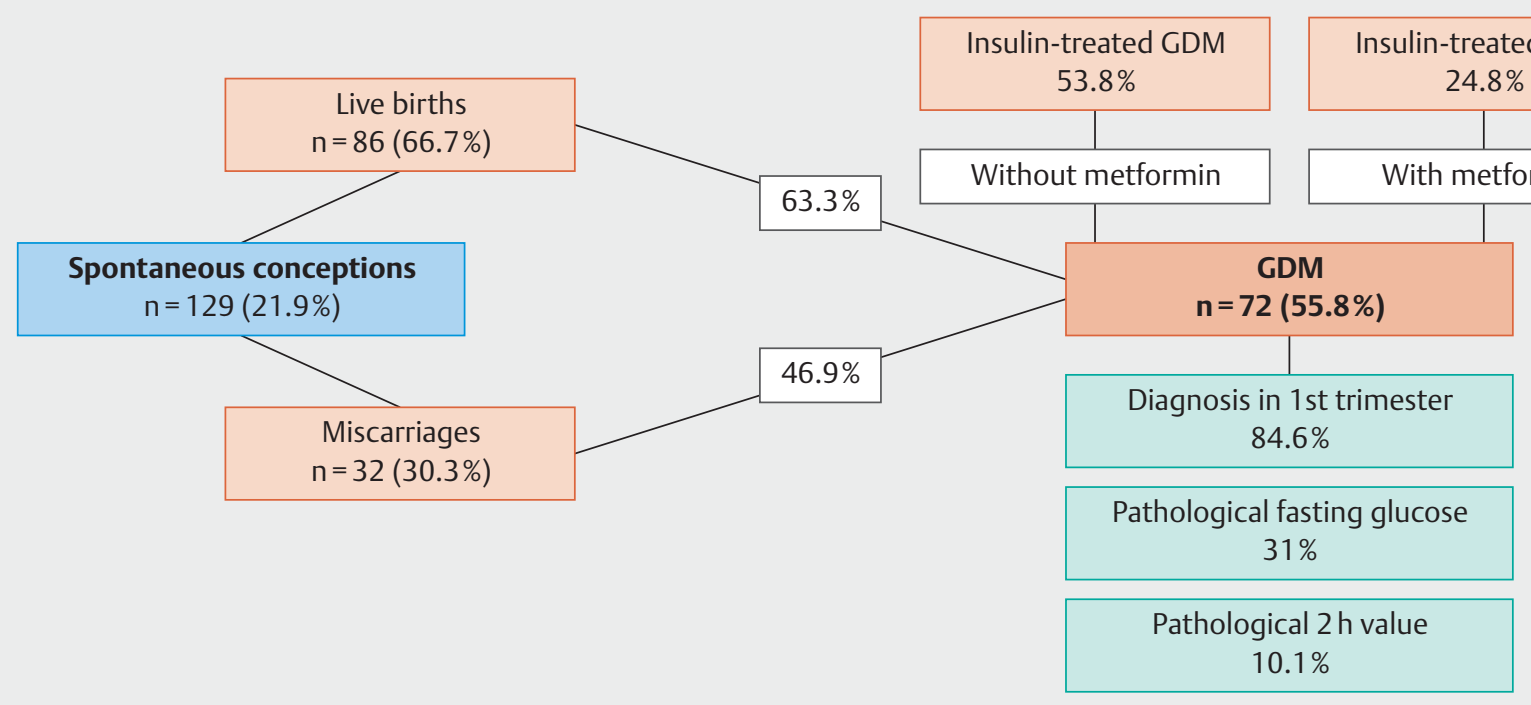

- Fig. 3 Schematic flow chart of the analyzed 129 spontaneous pregnancies categorized according to gestational diabetes and subdivided into pathologically abnormal OGTT results, treatment and pregnancy outcome.

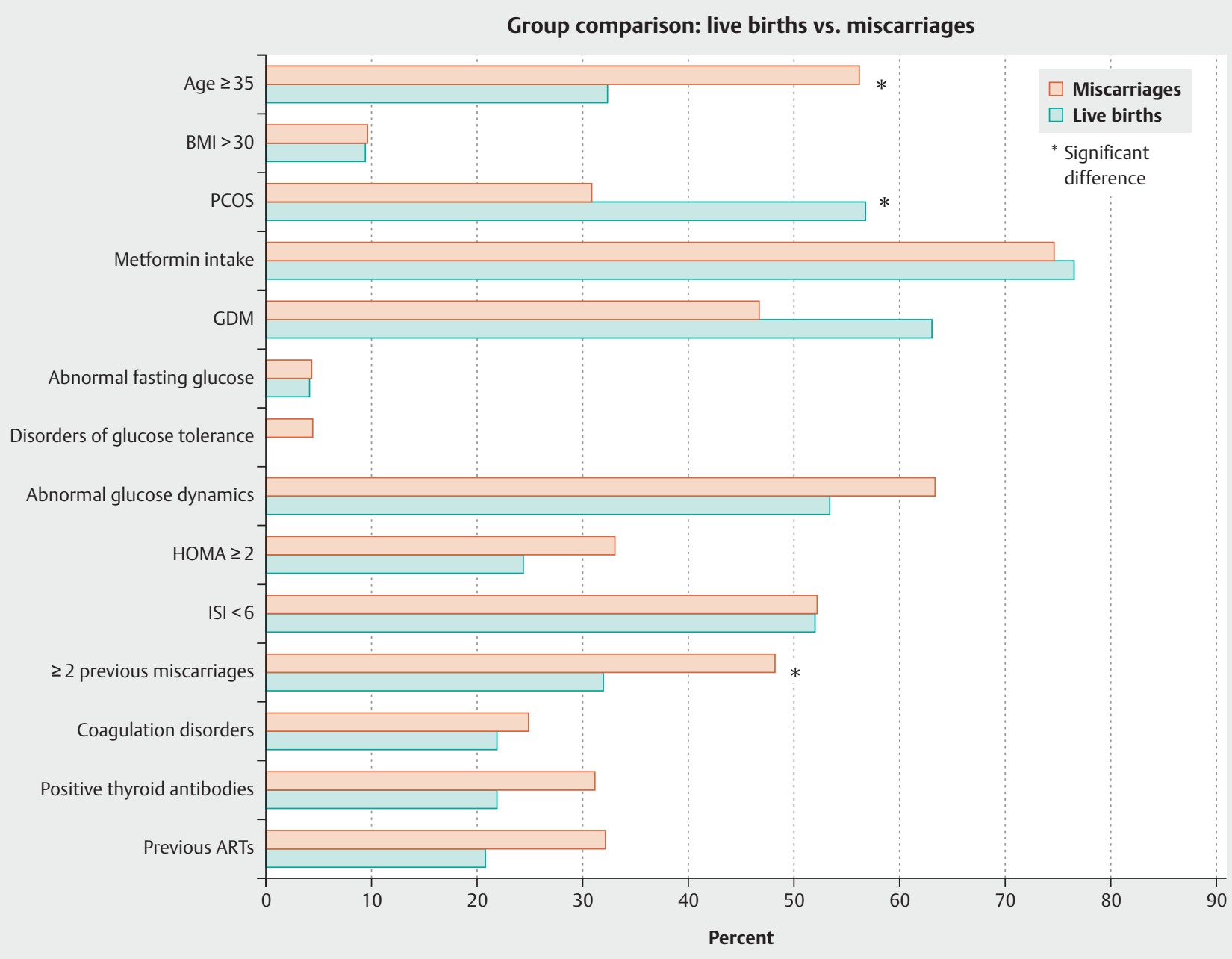

Fig. 4 Overview of the risk profile of the cohort who had miscarriages compared to the cohort who had live births. 


\section{Discussion}

The most important results of this study are:

1. the high rate of spontaneous conceptions (21.9\%) among women wishing to have children, which could be due to therapeutic optimization of disorders of glucose and insulin metabolism prior to conception;

2. the evidence that $70.0 \%$ of the participants in the study were of normal weight, which qualifies the increased risk of disorders of glucose and insulin metabolism due to obesity;

3. that $87.8 \%$ of the women who wanted to have children (highrisk cohort) had anomalous insulin levels even before conception; $76.0 \%$ of the total study population received treatment with metformin prior to conception;

4. that the GDM rate in the total cohort (high-risk cohort: women wanting to have children) was $55.8 \%$; in $84.6 \%$ of cases GDM was already diagnosed in the 1 st trimester of pregnancy;

5. that significantly fewer GDM patients developed insulin-dependent GDM if they received metformin.

\section{Overweight and obesity}

The prevalence of obesity both globally and in Germany has continually increased in recent years. The "Study on the Health of Adults in Germany" found that, in the period between 2008 and $2011,53.0 \%$ of women were pre-obese and $23.9 \%$ were obese [5]. In our study, $16.1 \%$ of patients were pre-obese and $9.7 \%$ were obese. The low prevalence of pre-obesity and obesity in our study population could be due to the relatively young patient age of the population and the usually higher social status of the women wishing to become pregnant, which is also associated with a lower prevalence of obesity in women [10]. The low obesity rate in our cohort qualifies the obesity-linked increased risk of disorders of glucose and insulin metabolism.

\section{Insulin resistance and metformin}

As regards insulin metabolism, there was a very high prevalence of insulin resistance in this study population (HOMA index: $26.0 \%$ abnormal values; ISI: $52.1 \%$ abnormal values; empirical insulin threshold values: $87.8 \%$ abnormal values). It should be noted that the HOMA index and the ISI are models which allow insulin resistance to be measured and compared, but the significance of data obtained in this context remains limited [11]. In our patient population, insulin resistance was not found to have a static association with developing GDM, with the rate of live births or with the rate of miscarriages. $76.0 \%$ of the study participants received treatment with metformin prior to conceiving. Recent studies have shown that metformin can also be used effectively and safely during pregnancy; some authors already recommend its use for the treatment and prevention of gestational diabetes [12-14]. Current studies showed no significant differences with regard to neonatal weight, gestational age, state of health, perinatal mortality and rate of preterm delivery between insulin and metformin used to treat GDM; however, rates of neonatal hypoglycemia in newborns were reduced in the GDM group treated with metfor$\min [12,15,16]$. Data from other studies have shown that metformin can even reduce the need for insulin in patients with GDM [17]. We were able to confirm this finding in our study. Of the
GDM patients treated with metformin, significantly fewer patients $(p=0.038)$ developed insulin-dependent GDM compared to the women who did not receive metformin. There was no significant difference in the overall rate of GDM between patients who had previously received metformin and those who did not. In the current GDM guideline, metformin is listed as an "off-label-use" drug option, also in combination with insulin, to treat GDM.

\section{GDM}

The GDM prevalence of $55.8 \%$ in this study is more than 4 times higher than in the normal population [9]. This would indicate that disorders of glucose and insulin metabolism may play an important role in the fertility problems of women of normal weight wishing to have children. In our study, GDM was diagnosed in $87.8 \%$ of cases already in early pregnancy as "early GDM" or "early-onset GDM". As many of the OGTTs carried out in early pregnancy were done during ongoing treatment with metformin, it can be assumed that the rate of early GDM was even higher. The data show that in a high-risk population with demonstrable risk factors for GDM, it is important not to wait with screening for GDM until the 24th week of gestation. Early diagnostic testing based on fasting glucose values carried out as part of $75 \mathrm{~g}$ OGTT and measurement of $\mathrm{HBA}_{1 \mathrm{c}}$ could help prevent implantation failure and metabolic problems.

\section{PCOS}

PCOS was diagnosed in $51.2 \%$ of analyzed patients. The GDM rate of PCOS patients was not significantly higher ( $59.1 \%$ vs. $52.4 \%$; $p=0.375)$. In the group of women who conceived spontaneously in our study population, the percentage of women with PCOS who had live births was significantly higher than the percentage of comparable PCOS patients who had miscarriages. It is known from the literature that PCOS patients in particular benefit from metformin treatment [18]. The administration of metformin to optimize insulin and glucose values prior to conception and at the time of implantation may help PCOS populations to conceive spontaneously and maintain a subsequent pregnancy.

\section{Age}

The risk of sterility and miscarriage rises with increasing the age, as does the risk of developing GDM [19]. Because of a lack of awareness about the impact of age on fertility [21], it would be best if the question of wanting to have children and the effect of older age is addressed on an outpatient basis. The average age of patients in our study was 33 years. $38.9 \%(n=50)$ of patients were more than 35 years of age. In 2014, 16.7\% of mothers in the general population were older than 35 years at delivery [20]. By comparison, the rate of women aged more than 35 years in our study population was $38.8 \%$ and thus significantly higher, which was clearly because the study cohort specifically consisted of women wanting to have children. Similarly, the comparison between two groups in our study population (miscarriage vs. live birth) showed a significant difference with respect to patient age. Overall, the rate of miscarriages in the group of women under the age of 35 years was $18.4 \%$, but the rate for women aged more than 35 years was $36.7 \%$. 


\section{Birth, birth weight and mode of delivery}

The C-section rate is higher for women with GDM than for the general population [22]. In our study, the C-section rate was $33.3 \%$ and thus was approximately the same as the average C-section rate in Germany reported for 2014 (32.9\%) [20]. The fact that the C-section rate in our study population was not higher than average, despite the high number of GDM patients, may also be a consequence of adjusting patients' metabolic factors, which largely prevented macrosomia. In addition to increasing the rate of C-sections, GDM also increases the risk of premature rupture of membranes, premature labor and, consequently, the rate of preterm births (5 times higher compared to the general population) [23]. Optimal glycemic control significantly reduces the risk of preterm birth [24]. In our study, $90.0 \%$ of births were at term, $8.3 \%$ were preterm births (moderate to late preterm) und $1.7 \%$ of neonates were born between the 28th and the 31st week of gestation (very preterm). The rate of preterm births for the GDM cohort was $7.0 \%$ and therefore not significantly higher than that of the comparison group without GDM. It is important to note that the number of evaluated births may be too low to be statistically relevant (missing data $\mathrm{n}=23$ ). The children of GDM patients have higher rates of macrosomia and are more likely to be "large for gestational age" [23]. A secondary but important risk of GDM with far-reaching consequences is intrauterine undernutrition, characterized by the symptom "small for gestational age" (SGA). Studies have shown that adults born with a lower birth weight were more likely to have disorders of glucose tolerance, insulin resistance and type 2 diabetes. Similarly, children with a low birth weight have a significantly higher cardiovascular risk and a higher risk of developing obesity, PCOS, and insulin resistance [25]. Intrauterine conditions and the epigenetic effects on children can increase the risk factors of the next generation for fertility disorders and abnormal glucose and insulin levels [26].

The Institute for Applied Quality Improvement and Research in Healthcare reported that in $201491.5 \%$ of children were born with a normal birth weight while $1.2 \%$ of children were born with a birth weight of more than $4500 \mathrm{~g}$ [20]. The median birth weight of the children in our study was $3250 \mathrm{~g}$; there was no difference between the children of GDM patients and those of non-GDM patients $(p=0.878)$.

\section{Limitations of the study}

The high rate of conception of more than $20 \%$ in our study is attributed to treating existing disorders of glucose metabolism prior to conception. The study is limited by the lack of a control group and the retrospective analysis of data. Moreover, other factors influencing sterility in the total study population were not included in the analysis. Prospective case control studies on the optimization of glucose/insulin metabolism and its impact on fertility are required to confirm the data presented here.

\section{Conclusion}

The results of the study support the hypothesis that successful metabolic optimization prior to conception may result in higher rates of spontaneous conception before starting ART. In addition, the high GDM rate among women with a history of sterility em- phasized the importance of evaluating glucose metabolism, including testing for insulin resistance, as disorders of glucose metabolism may be a crucial factor affecting sterility in infertile women. Evaluation of glucose metabolism is necessary to optimize the ovarian micro milieu for oocyte maturation and improve nidation conditions for the embryo. A hyperglycemic metabolic state and insulin resistance may contribute to preventing pregnancy or impair placental development by inhibiting trophoblast proliferation and thus adversely affect the course of pregnancy [8]. Such early disorders of placentation can lead to miscarriage in early pregnancy; moreover, inadequate placentation can also lead to complications of pregnancy such as preeclampsia [28, 29].

GDM has far-reaching consequences for mother and child. Preventive strategies are necessary to combat further increases in impaired glucose metabolisms [27]. Impaired maternal glucose metabolism can lead to negative fetal programming from DNA methylation and histon modifications, with far-reaching and long-term consequences for the child. It is known that children born to mothers with GDM have a higher risk of obesity, hyperlipidemia, arterial hypertension, PCOS and developing diabetes mellitus in early adulthood [30,31]. A close cooperation between physicians of reproductive medicine, gynecologists and diabetologists/endocrinologists is necessary and useful for systematic prevention, early recognition and early treatment of GDM. Such close cooperation could be the first step of preventive measures with positive epigenetic effects on glucose metabolism; early measures could thus help to avoid negative consequences for pregnant women and future generations.

\section{Acknowledgements}

Very special thanks go to the entire team of profertilita for the support and care offered to patients and to Ms. Helena Class and the Working Group for Early-onset Gestational Diabetes (AG FREG) for their help in preparing the design of the study, setting up the database, collecting the data and their critical and constructive analysis and discussion of the data.

\section{Conflict of Interest}

The authors declare that they have no conflict of interest.

\section{References}

[1] Ombelet W, Cooke I, Dyer S et al. Infertility and the provision of infertility medical services in developing countries. Hum Reprod Update 2008; 14: 605-621. doi:10.1093/humupd/dmn042

[2] Williams T, Mortada R, Porter S. Diagnosis and treatment of polycystic ovary syndrome. Am Fam Physician 2016; 94: 106-113

[3] Hart RJ. Physiological aspects of female fertility: role of the environment, modern lifestyle, and genetics. Physiol Rev 2016; 96: 873-909. doi:10.1152/physrev.00023.2015

[4] Pasquali R, Patton L, Gambineri A. Obesity and infertility. Curr Opin Endocrinol Diabetes Obes 2007; 14: 482-487. doi:10.1097/MED.0b013e $3282 \mathrm{f} 1 \mathrm{~d} 6 \mathrm{cb}$

[5] Mensink G, Schienkiewitz A, Haftenberger M et al. Übergewicht und Adipositas in Deutschland. Bundesgesundheitsbl 2013; 56: 786-794. doi:10.1007/s00103-012-1656-3 
[6] Balasch J, Gratacós E. Delayed childbearing. Curr Opin Obstet Gynecol 2012; 24: 187-193. doi:10.1097/GCO.0b013e3283517908

[7] S3-Leitlinie Gestationsdiabetes mellitus (GDM), Diagnostik, Therapie und Nachsorge 2017. Überarbeitungsversion. Online: https://www. deutsche-diabetes-gesellschaft.de/fileadmin/Redakteur/Leitlinien/ Leitlinien-zur-Konsultation/GDM-Leitlinie-_gesamttext.pdf; last access: 12.09.2017

[8] Weiss U, Cervar M, Puerstner $P$ et al. Hyperglycaemia in vitro alters the proliferation and mitochondrial activity of the choriocarcinoma cell lines BeWo, JAR and JEG-3 as models for human first-trimester trophoblast. Diabetologia 2001; 44: 209-219. doi:10.1007/s001250051601

[9] Melchior H, Kurch-Bek D, Mund M. The prevalence of gestational diabetes: a population-based analysis of a nationwide screening program. Dtsch Arztebl Int 2017; 114: 412-418. doi:10.3238/arztebl.2017.0412

[10] Zeiher J, Varnaccia G, Jordan S et al. Was sind die Einflussfaktoren kindlicher Adipositas? Bundesgesundheitsbl 2016; 59: 1465-1475. doi:10.1007/s00103-016-2441-5

[11] Wallace TM, Levy JC, Matthews DR. Use and abuse of HOMA modeling. Diabetes Care 2004; 27: 1487-1495. doi:10.2337/diacare.27.6.1487

[12] Rowan JA, Hague WM, Gao W et al. Metformin versus insulin for the treatment of gestational diabetes. N Engl J Med 2008; 358: 2003-2015. doi:10.1056/NEJMoa0707193

[13] Poolsup N, Suksomboon N, Amin M et al. Efficacy and safety of oral antidiabetic drugs in comparison to insulin in treating gestational diabetes mellitus: a meta-analysis. PLoS One 2014; 9: e109985. doi:10.1371/ journal.pone.0109985

[14] Butalia S, Gutierrez L, Lodha A et al. Short- and long-term outcomes of metformin compared with insulin alone in pregnancy: a systematic review and meta-analysis. Diabet Med 2017; 34: 27-36. doi:10.1111/ dme. 13150

[15] Niromanesh S, Alavi A, Sharbaf FR et al. Metformin compared with insulin in the management of gestational diabetes mellitus: A randomized clinical trial. Diabetes Res Clin Pract 2012; 98: 422-429. doi:10.1016/j. diabres.2012.09.031

[16] Spaulonci CP, Bernardes LS, Trindade TC et al. Randomized trial of metformin vs. insulin in the management of gestational diabetes. Am J Obstet Gynecol 2013; 209: 34.e1-34.e7. doi:10.1016/j.ajog.2013.03. 022

[17] McGrath RT, Glastras SJ, Hocking $S$ et al. Use of metformin earlier in pregnancy predicts supplemental insulin therapy in women with gestational diabetes. Diabetes Res Clin Pract 2016; 116: 96-99. doi:10.1016/j. diabres.2016.04.051

[18] Tan X, Li S, Chang Y et al. Effect of metformin treatment during pregnancy on women with PCOS: a systematic review and meta-analysis. Clin Invest Med 2016; 39: E120-E131
[19] Kentenich H, Jank A. Fortpflanzung im höheren Alter. Gynäkologische Endokrinologie 2016; 14: 105-110. doi:10.1007/s10304-016-0062-6

[20] AQUA-Institut. Bundesauswertung zum Erfassungsjahr 2014; 16/1 - Geburtshilfe; Qualitätsindikatoren. 2015. Online: www.sqg.de/downloads/ Bundesauswertungen/2014/bu_Gesamt_16N1-GEBH_2014.pdf; last access: 09.08.2016

[21] Hammarberg K, Clarke VE. Reasons for delaying childbearing-a survey of women aged over 35 years seeking assisted reproductive technology. Aust Fam Physician 2005; 34: 187-188, 206

[22] Sendag F, Terek MC, Itil IM et al. Maternal and perinatal outcomes in women with gestational diabetes mellitus as compared to nondiabetic controls. J Reprod Med 2001; 46: 1057-1062

[23] Michael Weindling A. Offspring of diabetic pregnancy: short-term outcomes. Semin Fetal Neonatal Med 2009; 14: 111-118. doi:10.1016/j. siny.2008.11.007

[24] Yogev Y, Langer O. Spontaneous preterm delivery and gestational diabetes: the impact of glycemic control. Arch Gynecol Obstet 2007; 276: 361-365. doi:10.1007/s00404-007-0359-8

[25] Dörr HG, Dötsch J. „Small for gestational age“ (SGA) - Risiko für ovarielle Hyperandrogenämie und PCO? Gynäkologische Endokrinologie 2005: 176-180. doi:10.1007/s10304-005-0119-4

[26] Ibáñez L, Potau N, Ferrer A et al. Anovulation in eumenorrheic, nonobese adolescent girls born small for gestational age: Insulin sensitization induces ovulation, increases lean body mass, and reduces abdominal fat excess, dyslipidemia, and subclinical hyperandrogenism. J Clin Endocrinol Metab 2002; 87: 5702-5705. doi:10.1210/jc.2002-020926

[27] Dempsey JC, Sorensen TK, Williams MA et al. Prospective study of gestational diabetes mellitus risk in relation to maternal recreational physical activity before and during pregnancy. Am J Epidemiol 2004; 159: 663670

[28] Metzger BE, Lowe LP, Dyer AR et al. Hyperglycemia and adverse pregnancy outcomes. N Engl J Med 2008; 358: 1991-2002. doi:10.1056/ NEJMoa0707943

[29] Schmitz S, Groten T, Schleussner E et al. Gestational diabetes mellitus: an evaluation of gynecologists' knowledge of guidelines and counseling behavior. Arch Gynecol Obstet 2016; 294: 1209-1217. doi:10.1007| s00404-016-4161-3

[30] Damm P, Houshmand-Oeregaard A, Kelstrup L et al. Gestational diabetes mellitus and long-term consequences for mother and offspring: a view from Denmark. Diabetologia 2016; 59: 1396-1399. doi:10.1007| s00125-016-3985-5

[31] Hakanen T, Saha MT, Salo MK et al. Mothers with gestational diabetes are more likely to give birth to children who experience early weight problems. Acta Paediatr 2016; 105: 1166-1172. doi:10.1111/apa.13468 